\title{
SOSIALISASI TEKNIK PENANGKARAN PENYU BERBASIS EKOWISATA DI PANTAI GUGOP KECAMATAN PULO ACEH KABUPATEN ACEH BESAR PROVINSI ACEH
}

\section{THE SOSIALIZATION OF TURTLE ECOTOURISM BASED IN THE GUGOP BEACH PULO ACEH DISTRICT ACEH BESAR REGENCY ACEH PROVINCE}

\author{
Rika Astuti ${ }^{1}$ \\ ${ }^{1}$ Program Studi Sumberdaya Akuatik, Fakultas Perikanan dan IImu Kelautan, Universitas Teuku Umar \\ Korespondensi: rika.astuti87@yahoo.com
}

\begin{abstract}
ABSTRAK
Penyu merupakan reptil laut yang menghuni ekosistem lamun dan mampu bermigrasi jauh di sepanjang kawasan Samudera Hindia, Samudera Pasifik hingga Asia Tenggara. Penyu yang tersebar di perairan tropis dan subtropik sebagian besar banyak ditemukan di perairan Indonesia khususnya di perairan Aceh. Pantai barat Aceh Besar, khususnya Pulo Aceh saat ini memiliki potensi sebagai tempat berdiamnya beberapa populasi penyu. Beberapa spesies penyu yang sering bertelur di pantai ini adalah penyu lekang, penyu belimbing dan penyu hijau. Adapun tujuan dari pengabdian ini adalah untuk memberikan pemahaman kepada Kelompok Lembaga Ekowisata Pulo Aceh (LEPA) dan masyarakat disekitar lokasi Pulo Aceh untuk memahami pentingnya pelestarian penyu, dan dapat mengimplementasikan teknik penangkaran penyu untuk pengembangan ekowisata di Pulo Aceh yang baik dan keberlanjutan. Kegiatan Pengabdian ini dilakukan selama dua hari, yakni mulai hari sabtu tanggal 10 maret sampai hari minggu tanggal 11 maret 2018 bertempat di Pantai Gugop, Pulo Aceh, Kabupaten Aceh Besar, Provinsi Aceh. Pendekatan yang dilakukan dalam kegiatan ini adalah sosialisasi secara persuasif dan praktek langsung teknik penangkaran penyu serta pelepasan tukik penyu yang dihadiri oleh wisatawan dari berbagai daerah, instansi Pemerintah, lembaga swadaya masyarakat dan akademisi di Aceh. Tukik penyu yang dilepaskan sebanyak 270 ekor dari total 480 ekor, yang terdiri dari 2 jenis; yakni Penyu Lekang sebanyak 353 ekor, yang dilepaskan 170 ekor. Sedangkan penyu hijau sebanyak 127 ekor, yang dilepaskan hanya 100 ekor. Tukik-tukik yang ditinggalkan tersebut berada di lokasi penangkaran yang bertujuan untuk ekowisata dan penelitian bagi akademisi untuk melakukan penelitian terhadap satwa yang dilindungi dan terancam punah ini.
\end{abstract}

Kata kunci : Penyu, Pulo Aceh, penangkaran penyu, ekowisata.

\begin{abstract}
Turtles are marine reptiles that inhabit seagrass ecosystems and are able to migrate deeply along the Indian Ocean, Pacific Ocean to Southeast Asia. Turtles are scattered in tropical and subtropical waters mostly found in Indonesian waters, especially in Aceh waters. The west coast of Aceh Besar, especially Pulo Aceh currently has potential as a residence for several turtle populations. Some of the turtle species that often lay their eggs on this beach are turtles, leatherback turtles and green turtles. The purpose of this dedication is to provide understanding to the Pulo Aceh Ecotourism Institute (LEPA) and communities around Pulo Aceh to understand the importance of turtle conservation, and to implement turtle breeding techniques for ecotourism development in good Pulo Aceh and sustainability. This devotional activity is carried out for two days, ie from Saturday to 10 March to Sunday 11 March 2018 held at Gugop Beach, Pulo Aceh, Aceh Besar District, Aceh Province. The approach taken in this activity is the persuasive socialization and the direct practice of turtle conservation techniques and the release of sea turtles attended by tourists from various regions, government agencies, non-governmental organizations and academics in Aceh. Turtle turtles are released as much as 270 head of 480 total tail, which consists of 2 types; namely Turtle Lekang as many as 353 heads, which released 170 tails. While the green turtle of 127 tails, which is released only 100 tails. The abandoned hatchlings are in a breeding location aimed at ecotourism and research for academics to conduct research on these endangered and endangered animals.
\end{abstract}

Key words: Turtle, Pulo Aceh, turtle conservation, ecotourism. 


\section{PENDAHULUAN}

Aceh memiliki wilayah pesisir dan laut terbesar di Pulau Sumatera. Aceh memiliki 18 kabupaten/kota di wilayah pesisir dengan panjang garis pantai Aceh 2.666,27 km, luas wilayah laut kewenangan $43.339,83 \mathrm{~km}^{2}$, luas hutan mangrove $30.907,41 \mathrm{ha}$, luas terumbu karang $15.124,57$ ha dan luas lamun 539,68 ha. Dari data tersebut menunjukkan begitu komplek permasalahan di pesisir dan laut Aceh, dan salah satunya adalah terancamnya kelestarian penyu di pesisir Aceh yang mempunyai panjang garis pantai sepanjang 2.666,27 km (DKP, 2013).

Kabupaten Aceh Besar adalah salah satu kabupaten yang mempunyai panjang garis pantai terpanjang di Propinsi Aceh yaitu sepanjang $344 \mathrm{~km}$ dengan luas wilayah perairan laut $2.796 \mathrm{~km}^{2}$, jumlah pulau-pulau kecil sebanyak 21 buah, pulau-pulau terluar 2 buah, 8 kecamatan pesisir dan 83 gampong pesisir. Potensi sumber daya pesisir dan laut yang dimiliki Aceh Besar antara lain luas terumbu karang 1.155 ha dan luas ekosistem mangrove 133,94 ha (DKP Aceh Besar, 2015). Untuk menjaga dan melestarikan sumber daya di pesisir dan laut tersebut, Aceh Besar mencadangkan Kawasan Konservasi Perairan (KKP) di 15 kawasan dengan dikeluarkannya SK Bupati Aceh Besar No. 190 Tahun 2011 tentang Pembentukan Kawasan Konservasi Perairan (KKP) di Kabupaten Aceh Besar.

Pulo Aceh merupakan salah satu Kecamatan dari 23 Kecamatan yang ada di Kabupaten Aceh Besar dan merupakan satu-satunya Kecamatan Kepulauan di Kabupaten Aceh Besar, yang terbentuk berdasarkan PP No 5 tahun 1983 dengan Ibukota Kecamatan Lampuyang. Selanjutnya berdasarkan UU nomor 37 tahun 2000 Kecamatan Pulo Aceh juga termasuk dalam Wilayah Perdagangan Bebas dan Pelabuhan Bebas Sabang. Selain itu, Pulo Aceh merupakan Daerah Administrasi Tingkat III yang terletak paling barat di Indonesia. Kecamatan Pulo Aceh juga termasuk dalam salah satu Kawasan Konservasi Perairan yang dicadangkan dengan berbagai potensi di sektor kelautan, perikanan dan pariwisata.

Salah satu ikon wisata yang baru dikembangkan di Pantai Gugop, Pulo Aceh ini adalah kegiatan penangkaran penyu. Kegiatan ini diinisiasi oleh kelompok Lembaga Ekowisata Pulo Aceh (LEPA) dan Panglima Laot Lhok setempat dan juga dukungan Pemerintah Aceh Besar dan sejumlah lembaga penggiat konservasi seperti Yayasan Lamjabat, WCS-Indonesia Marine Program dan WWF-Indonesia. Penangkaran penyu dilakukan sebagai salah satu strategi untuk membangun kesadaran dan dukungan publik, baik masyarakat setempat maupun pengunjung, bahwa diperlukan tindakan konservasi dengan berbagai pilihan pendekatan yang bersifat partisipatif dan kolaboratif dalam perlindungan penyu.

Berdasarkan informasi dari masyarakat setempat, pantai Gugop ini menjadi pantai peneluran (nesting beach), untuk berbagai jenis penyu seperti: penyu hijau (Chelonia mydas), penyu lekang (Lepidochelys olivacea) dan penyu belimbing (Dermochelys coriacea) (WWF, 2008). Namun pada tahun ini (2018) hanya 2 jenis penyu saja yang berhasil ditemukan sarang telurnya. masyarakat juga menuturkan bahwa jumlah indukan penyu yang mendarat pada setiap periode puncak peneluran terus berkurang dan diperkirakan saat ini tidak lebih dari 5-7 indukan saja.

Tujuan pelaksanaan kegiatan pengabdian ini adalah untuk memberikan pemahaman dan pengetahuan pentingnya pelestarian penyu kepada kelompok Lembaga Ekowisata Pulo Aceh (LEPA) dan masyarakat disekitar lokasi Pulo Aceh, 
khususnya di Gampong Gugop, dan dapat mengimplementasikan teknik penangkaran penyu untuk pengembangan ekowisata di Pulo Aceh yang baik dan keberlanjutan dengan kearifan lokalnya secara baik dan berkelanjutan.

\section{METODELOGI}

Pelaksanaan kegiatan pengabdian ini dilakukan selama dua (2) hari, yaitu pada tanggal 10 Maret 2018 sampai dengan 11 Maret 2018. Lokasi pengabdian ini dilakukan di Pantai Gugop, Gampong Gugop, Kecamatan Pulo Aceh, Kabupaten Aceh Besar, Provinsi Aceh (Gambar 1).

Teknik pendekatan yang digunakan terhadap persoalan mitra adalah metode ceramah dan praktikum. Metode ceramah dilakukan dengan cara memberikan penyuluhan secara langsung kepada kelompok Lembaga Ekowisata Pulo Aceh (LEPA) dan masyarakat sekitar Pulo Aceh tentang konservasi penyu, agar dapat menumbuhkan kesadaran masyarakat pesisir untuk mempertahankan populasi penyu di Aceh.

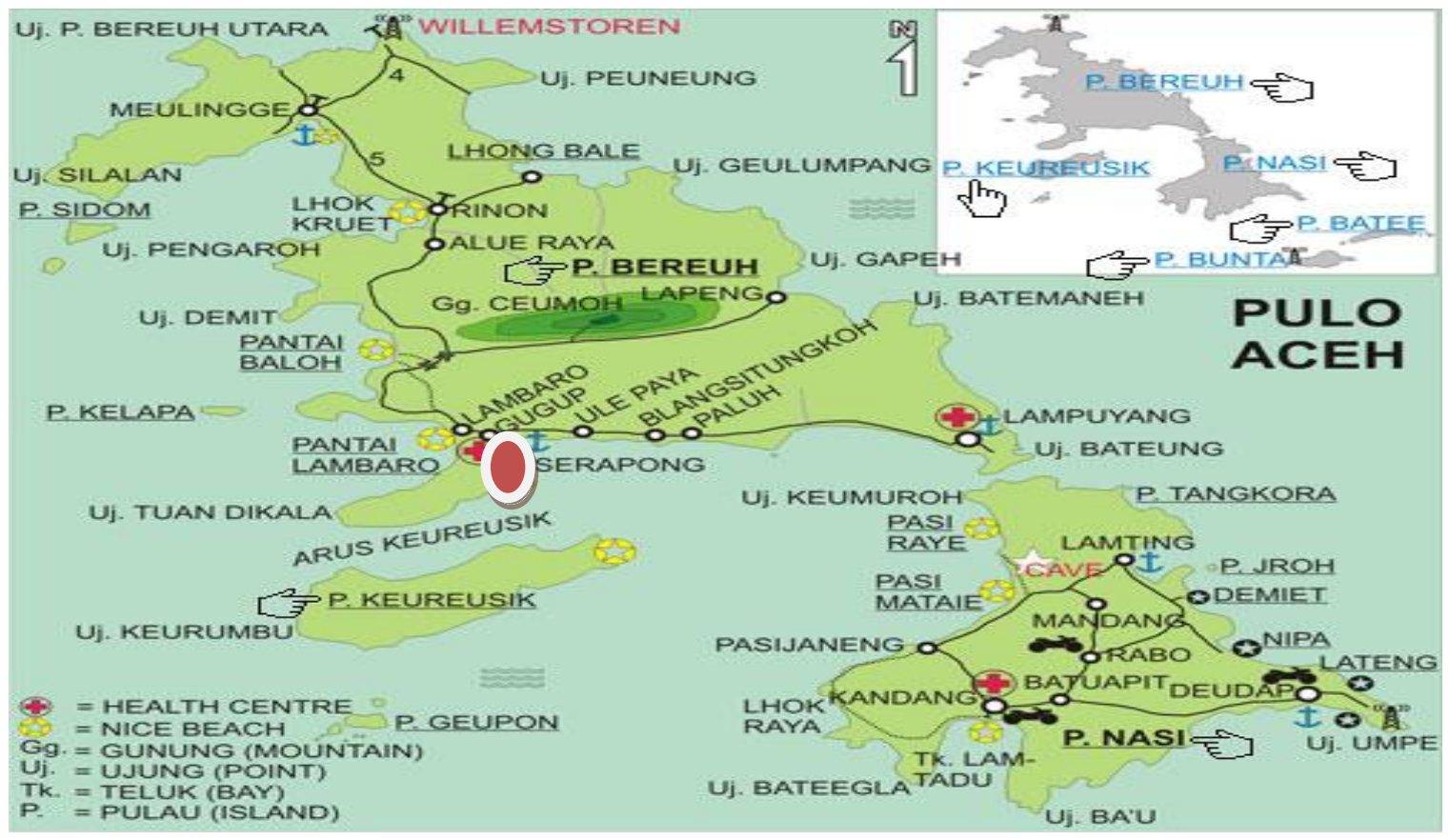

Gambar 1. Peta lokasi Kegiatan Pengabdian

Sumber : (WCS-Marine, 2017).

Metode praktikum dilakukan dengan cara melakukan penangkaran alami ditempat penangkaran penyu di pantai Gugop, dan aksi nyata pelepasan tukik (anakan penyu) yang disaksikan oleh masyarakat sekitar, wisatawan dan beberapa tamu yang hadir dari berbagai instanti pemerintahan baik dari Pusat, Provinsi maupun daerah (Kabupaten Aceh Besar). Hal ini mendorong untuk kegiatan promosi ekowisata di Pulo Aceh. 
Adapun langkah-langkah yang dilakukan terdiri dari:

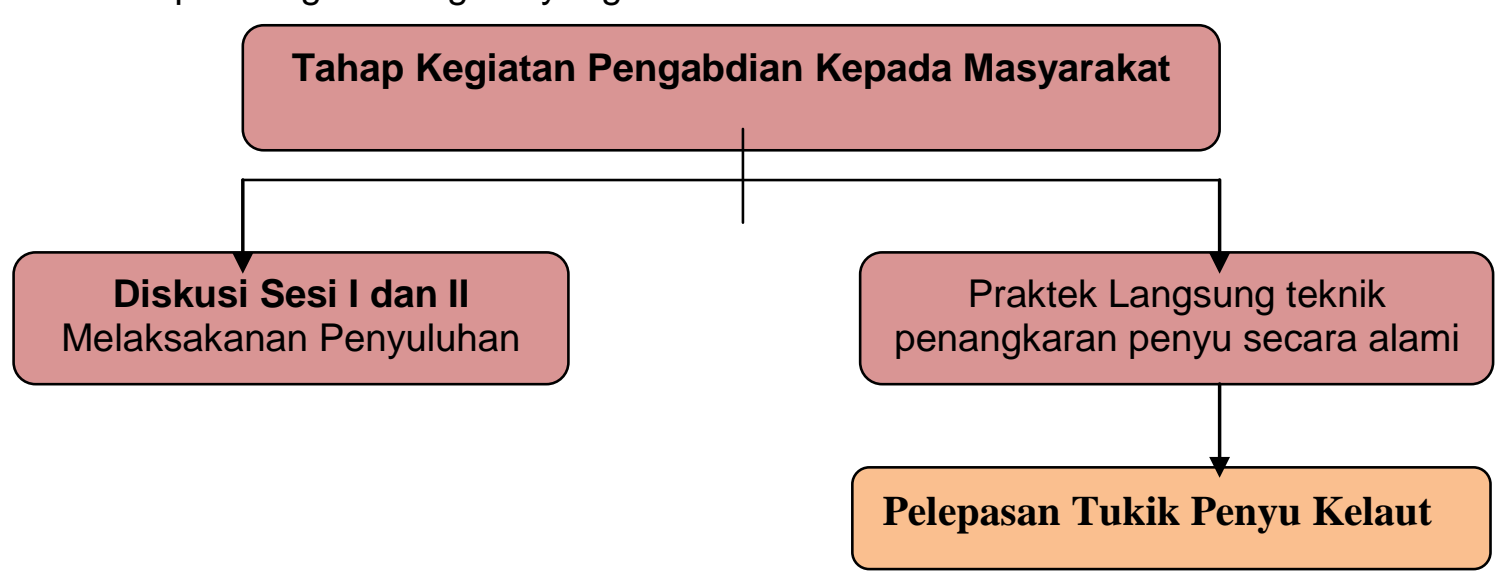

Gambar 2. Tahapan Pelaksanaan kegiatan pengabdian masyarakat

\section{HASIL DAN PEMBAHASAN}

\section{Kegiatan Sosialisasi Konservasi Penyu}

Sosialisasi konservasi penyu dilakukan melalui diskusi, yang terdiri dari 2 sesi diskusi. Sesi pertama (I) narasumbernya dari pihak Kementrian Kelautan dan Perikanan (KKP) yakni Bapak M. Saefudin, kemudian Bapak Agus Husni Kepala Dinas Kelautan dan Perikanan Aceh Besar, dan Bapak Zainal Arifin Lubis selaku Direktur Bank Indonesia (BI) Aceh. Pada sesi diskusi kedua (II) narasumbernya terdiri dari akademisi Unversitas Teuku Umar, Lembaga Swadaya Masyarakat (WCS-marine dan Yayasan Lamjabat). Masing-masing sesi diskusi narasumbernya terdiri dari 3 orang.

Hasil pengamatan selama kegiatan berlangsung menunjukkan bahwa pemahaman peserta terhadap pelestarian penyu sangat baik, walaupun masih ada sebagian peserta yang belum mengetahui tentang seberapa jauh peran pelestarian penyu untuk lingkungan pesisir bagi kawasan wisata di Pulo Aceh. Hal ini dapat dilihat dari pertanyaan-pertanyaan yang dimunculkan pada saat diskusi berlangsung. Adapun beberapa pertanyaan yang diajukan adalah bagaimana kami bisa menarik wisatawan untuk datang ke Pulo Aceh ini untuk melihat konservasi penyu yang sudah kami jalankan ini, apa saja yang harus dipersiapkan jika wisatawan sudah tertarik datang kesini, dan untuk prospek kedepannya bagaimana cara mengembangkan pariwisata di Pulo Aceh ini yang jauh dari perkotaan yang masih mengandalkan kearifan lokal disini dengan adat istiadat yang masih jauh ketertinggalan jika dibandingkan daerah-daerah lainnya.

Harapan peserta dengan adanya diskusi ini ada upaya tindak lanjut untuk melakukan pendampingan secara teknis bagi kelompok Lembaga Ekowisata Pulo Aceh (LEPA) pada saat-saat musim peneluran penyu untuk tahun yang akan datang. Selain itu peserta berharap juga adanya pendampingan dan bimbingan dalam upaya pengembangan wisata bahari di Pulo Aceh untuk mendatangkan wisatawan dari luar, dan untuk sarana dan prasarana peserta mengharapkan adanya perhatian dan bantuan dari pihak pemerintah baik pusat maupun daerah serta lembaga Bank Indonesia untuk pengembangan ekowisata di Pulo Aceh ini. 


\section{Simulasi dan Praktek Teknik Penangkaran Penyu Melakukan Penangkaran}

Penangkaran penyu pada prinsipnya merupakan salah satu upaya untuk menyelamatkan populasi penyu agar tidak punah (Direktorat Konservasi, 2009), dengan meningkatkan daya tahan tubuh penyu dari berbagai gangguan, termasuk penyakit, menjauhkan penyu atau tukik dari hal-hal yang membahayakan kehidupannya (misal dari predator) dan meningkatkan daya tetas telur penyu (Hanneke, 2002). Oleh karena itu, stasiun penangkaran penyu harus berada pada sekitar habitat peneluran penyu (Sani, 2000). Adapun lokasi penangkarannya adalah di Pantai Gugop, Pulo Aceh. Tempat penangkaran yang dibuat masih bersifat alami (Gambar 3).

Telur-telur penyu yang berada di tempat penangkaran berasal dari pantai setempat yang direlokasi oleh kelompok LEPA. Telur-telur tersebut telah dikemas menggunakan ember dan siap di tanam kembali di lokasi penangkaran dengan ukuran kedalaman yang sama seperti yang alami.

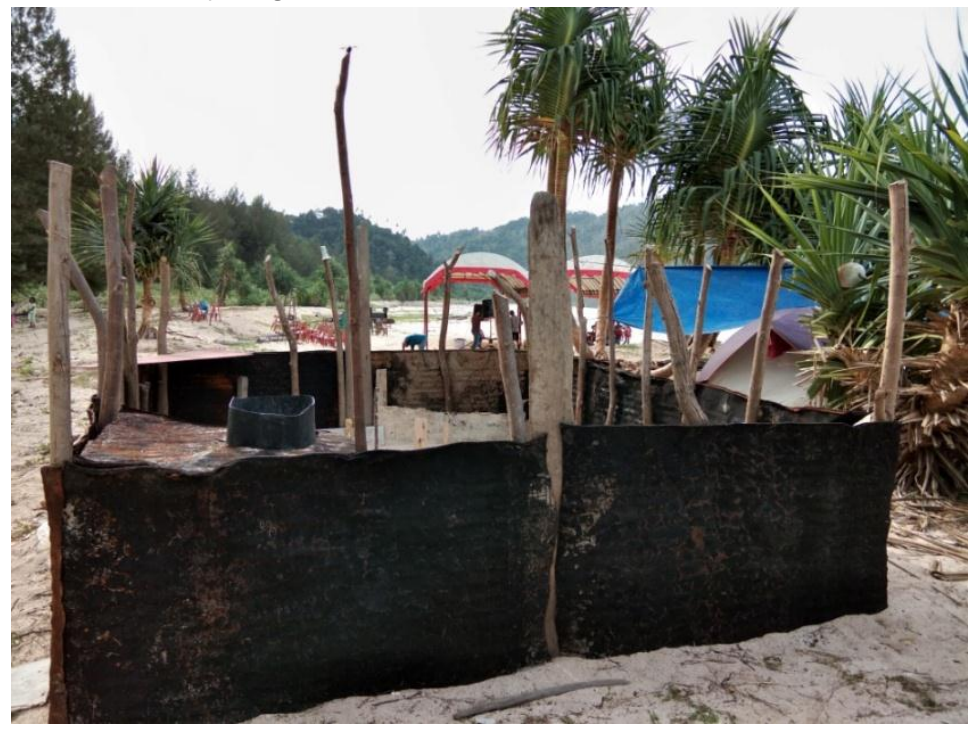

Gambar 3. Tempat penangkaran penyu alami

Kegiatan-kegiatan yang dilakukan di stasiun penangkaran penyu secara garis besar diantaranya:

1. Menjaga telur-telur penyu dari berbagai potensi ancaman hingga menetas menjadi tukik dan tukik kembali dilepaskan ke laut dengan aman.

2. Tempat sementara bagi tukik-tukik yang baru menetas dan siap untuk dilepaskan secepatnya ke laut.

3. Pemberian pakan yang cukup, sehat dan bergizi bagi tukik, supaya anak penyu sehat dan tahan penyakit.

4. Menciptakan kondisi lingkungan perairan yang sehat dan memenuhi syarat ekologi.

5. Melakukan karantina terhadap penyu-penyu yang berpenyakit.

6. Memelihara dan merawat tukik yang bertujuan untuk ekowisata dan pendidikan/penelitian. 


\section{Pelepasan Tukik}

Pelepasan tukik dilaksanakan pada hari minggu tanggal 11 Maret 2018. Acara ceremony pelepasan dilaksanakan serentak untuk kedua sarang mengingat ini adalah pengalaman pertama dan juga antusias masyarakat untuk menyaksikan pelepasan sangatlah tinggi. Pelepasan di mulai pukul $17.00 \mathrm{Wib}$, mengingat aktifitas predator laut sudah mulai berkurang sehingga persentase keselamatan tukik-tukik yang dilepaskan lebih tinggi.

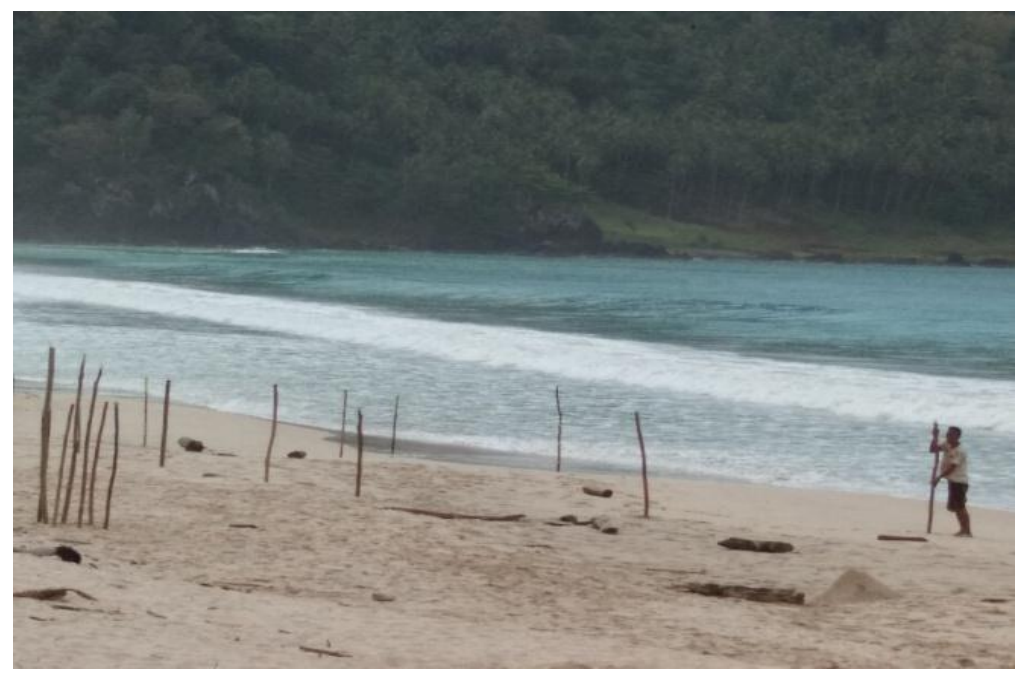

Gambar 4. Batasan pada saat pelepasan Tukik Penyu

Tukik yang dilepaskan sebanyak 270 ekor dari total 480 ekor, yang terdiri dari 2 jenis; yakni Penyu Lekang sebanyak 353 ekor, yang dilepaskan 170 ekor saja. Sedangkan penyu hijau sebanyak 127 ekor, yang dilepaskan hanya 100 ekor. Tukiktukik yang ditinggalkan tersebut berada di lokasi penangkaran yang bertujuan untuk ekowisata dan kedepannya dapat menjadi bahan penelitian bagi akademisi yang ingin melakukan penelitian terhadap satwa yang dilindungi dan terancam punah ini.

Pelepasan tukik dilakukan secara simbolis oleh Direktur KKHL-PRL-KKP Pusat, Kepala DKP Kabupaten Aceh Besar, Sekda Bupati Aceh Besar dan juga perwakilan mahasiswa Unsyiah Fakultas Kelautan dan Perikanan, Fakultas Kedokteran Hewan, dan Fakultas MIPA, serta masyarakat umum yang berdomisili di Pulo Aceh.

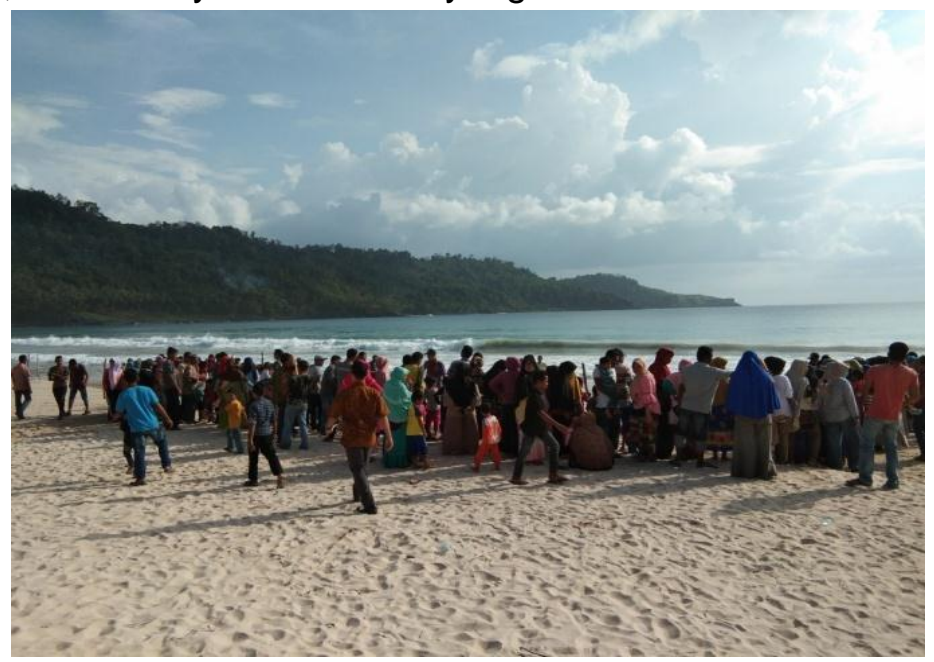

Gambar 5. Antusias peserta melakukan pelepasan tukik 
Prinsip pelepasan tukik yang dilakukan disini adalah pelepasan tukik secepat cepatnya dan bersamaan, begitu mereka menetas lalu muncul ke permukaan tanah/pasir, maka tukik-tukik tersebut harus segara dilepaskan ke laut agar insting alam dan cadangan makanan cukup untuk menempuh perjalanan yang dirasakan aman menurut tukik-tukik tersebut (WWF, 2009).

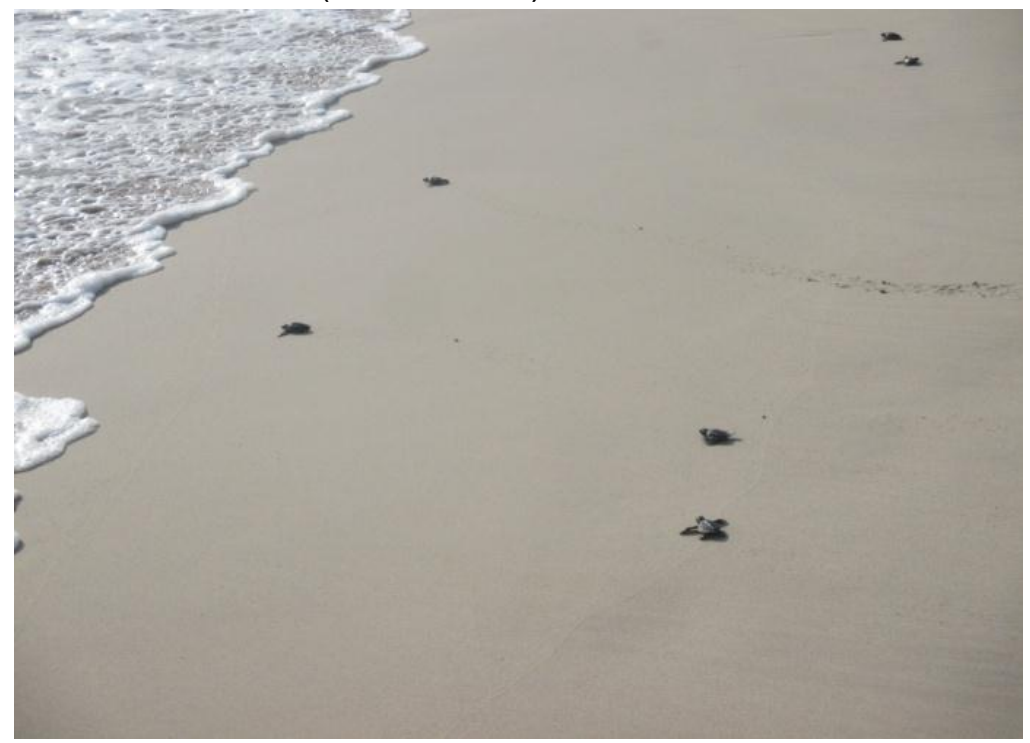

Gambar 6. Tukik penyu menuju kelaut

\section{KESIMPULAN}

Kegiatan sosialisasi dan pelatihan teknik penangkaran penyu ini dapat terselenggara dengan baik dan berjalan lancar sesuai dengan rencana kegiatan yang telah disusun. Kegiatan ini mendapat sambutan sangat antusias dari berbagai pihak, baik dari tingkat Pusat (KKP), daerah (DKP Aceh Besar dan Pemkab Aceh Besar), serta lembaga Bank (BI). Hal ini dapat dibuktikan dengan kehadiran menjadi narasumber pada saat sesi diskusi I dan II. Peserta yang hadir pun juga dari berbagai kalangan/pihak, akan tetapi khusus untuk simulasi teknik penangkaran penyu hanya difokuskan bagi kelompok Lembaga Ekowisata Pulo Aceh (LEPA). Sampai berakhirnya kegiatan peserta mengikutinya dengan baik.

\section{UCAPAN TERIMA KASIH}

Ucapan terima kasih disampaikan kepada:

1. Kelompok Lembaga Ekowisata Pulo Aceh (LEPA) atas kerjasama dan kekompakan dalam mensukseskan seluruh rangkaian kegiatan ini dari awal sampai akhir kegiatan.

2. Kegiatan ini merupakan kolaborasi kegiatan antar berbagai lembaga dan instansi baik pemerintahan, maupun Lembaga Swadaya Masyarakat. Terima kasih kepada Yayasan Lamjabat dan WCS yang sudah membantu mensukseskan acara ini. Kementrian Kelautan dan Perikanan (KKP), Kepala Dinas Kelautan dan Perikanan Aceh Besar yang telah menjadi narasumber.

3. Bank Indonesia (BI) yang telah menjadi narasumber dan mensponsori seluruh kegiatan ini. 


\section{DAFTAR PUSTAKA}

Direktorat Konservasi dan Taman Nasional Laut, Direktorat Jenderal Kelautan, Pesisir dan Pulau-Pulau Kecil, Departemen Kelautan dan Perikanan RI.2009. "Pedoman Teknis Pengelolaan Konservasi Penyu".

[DKP] Dinas Kelautan dan Perikanan Aceh Besar. 2015. Data Statistik Perikanan Aceh. Kota Jantho. 64p.

[DKP] Dinas Kelautan dan Perikanan Aceh. 2013. Data Statistik Perikanan Aceh. Banda Aceh. 85p.

Hanneke Nooren dan Gordon Claridge (Maret 2002), Panduan pengelolaan penangkaran penyu, Turtle Foundation, Hauptstr. 1, D-82541, Ammerland, Germany.

Sani, A. A. 2000. Karakteristik Biofisik Habitat Peneluran Dan Hubungannya Dengan Sarang Peneluran Penyu Hijau (Chelonia mydas) Di Pantai Sindang Kerta, Cipatujah, Tasikmalaya, Jawa Barat. Skripsi. Institut Pertanian Bogor. Bogor. $68 p$.

WWF. 2008. Tiga Negara Sepakat Lindungi Penyu Belimbing. http://www.wwf.or.id/ 2008/ tiga-negara-sepakat-lindungi-penyu- belimbing.html.

WWF. 2009. Buku panduan melakukan pemantauan populasi penyu di pantai peneluran penyu di Indonesia. Universitas Udayana. 